\title{
A Paulownia coreana Box for Storage of Annals of Joseon Dynasty: Its Efficacy and Functionality Evaluations of Temperature and Relative Humidity Control, and Microbe and Insect Repellent Activity
}

\author{
Hae Jin Park, Seon Hye Jeong, Hyun Ju Lee, Na Ra Lee, Yong Jae Chung \\ Department of Heritage Conservation and Restoration, Graduate School of Cultural Heritage, \\ Korea National University of Cultural Heritage, Buyeo 33115, Korea
}

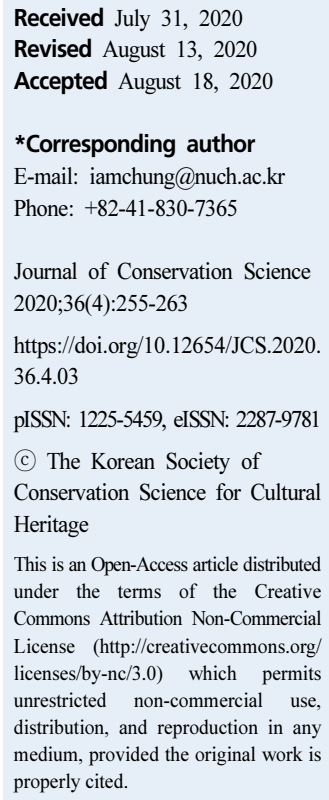

\begin{abstract}
Paulownia coreana has various advantages as a convenient workability, aesthetic outlook, beautiful patterns, low weight and high strength, and its permeability. P. coreana has been widely used for storage but there are no empirical researches proving its functionality in a field of conservation science until now. In this study, the seasonal and daily temperature and relative humidity control, and microbe and insect repellent activity were evaluated under the controlled and uncontrolled circumstances from 2015 to 2016 . The results showed to be mainly excellent in relative humidity control and the buffering effect was good to adjust the average daily relative humidity range from the outside. With respect to the antimicrobial properties of $P$. coreana, we observed that its water-soluble extract produced visible zones of inhibition against five bacteria. However, it was difficult to predict the antimicrobial and/or insecticidal properties.
\end{abstract}

Key Words Paulownia coreana box, Storage box, Functionality, Temperature and relative humidity control, Microbe and insect repellent activity

\section{INTRODUCTION}

The storage boxes made with wood materials have been traditionally used to preserve the paper and textile objects for a long-term storage in not only Korea but also near countries as China and Japan. The wood has been used as a variety of household goods, furnitures, and architecture materials since ancient period due to its various advantages as convenient workability, aesthetic outlook and outstanding patterns, low weight and high strength, and its permeability. Following the analysis results of eighty-two wooden species from the furnitures dated from late Joseon Dynasty and possessed by the Seoul Museum of History, 7\% of wooden species was identified as Paulownia spp. It is mainly used for inner drawers' material because of its lightweight, low-specific gravity and low strain rate (Song et al., 2010). Among them, $P$. coreana belongs to the family of Scrophulariaceae with a very clear ring and the colour is either light purple or pale rose pink with unclear distinction between the sapwood and heartwood. $P$. coreana is widely used in various appliances and furnitures because of its fast growth and low absorbency. Following the published researches, it is known well that the air-dried gravity of $P$. coreana is low to 0.24 and also easy to control humidity (Lee et al., 2004). So it has been applied 
for making the boxes and furniture in storage and/or display spaces to preserve the small-sized artifacts such as costumes, papers, archives and paintings (Park, 2005; Chung et al., 2008; Cho, 2011).

Even though it is known well that it has peculiar characteristics such as low weight, little cracking and/or splitting, relative humidity control and insect repellent, an empirical researches has not been reported to probe its functionality of the material itself. In this study, we tried to verify empirically its functionality by evaluating the temperature and relative humidity control, and microbe and insect repellent activity of $P$. coreana box.

\section{MATERIAL AND METHOD}

\subsection{Temperature and Relative Humidity Control}

Two comparative spaces were set up to identify the temperature and relative humidity control of $P$. coreana: (1) a national storage room controlled with thermo-hygrostat equipment at the Kyujanggak Institute for Korean Studies (Seoul National University, Seoul) and (2) the Korean traditional architecture without any thermo-hygrostat systems at the Anguk-dong detached palace (Korea National University of Cultural Heritage, Buyeo). Each 5 data loggers $(174 \mathrm{H}$, Testo, DEU) were installed and recorded with 30 minutes intervals from October 2015 to September 2016 at the Kyujanggak Institute for Korean Studies and Anguk-dong detached palace.

The locations were selected to measure the controlled temperature and relative humidity at the Kyujanggak Institute for Korean Studies: inner newly-fabricated $P$. coreana box $($ W930 $\times$ L380 $\times$ H312 mm, T15 mm), inner old P. coreana box $(\mathrm{W} 930 \times \mathrm{L} 380 \times \mathrm{H} 312 \mathrm{~mm}, \mathrm{~T} 15 \mathrm{~mm})$ that had been used to store the Annal of Joseon Dynasty in the past (Accession number: storage box of Annal of the Joseon Dynasty, Sil-03), inner newly fabricated Pseudotsuga menziesii storage box (W930 × L380 × H312 mm, T15 mm) as a control group, $P$. coreana corridor as an open space, and inner sealed $P$. coreana furniture as a close space (Figure 1). Also, 5 locations were chosen to identify its self-regulating control under uncontrolled circumstances without any thermohygrostat equipment at the Anguk-dong detached palace: inner newly-fabricated $P$. coreana and $P$. menziesii wooden box located in room, inner room, inner newly- fabricated $P$. coreana box located outdoor, and the outside (Figure 2).

\subsection{Active ingredient extraction from wood materials}

Prior to evaluating the microbe and insect repellent activity of $P$. coreana, active ingredient was extracted from wood materials and $P$. menziesii was used as a control group.

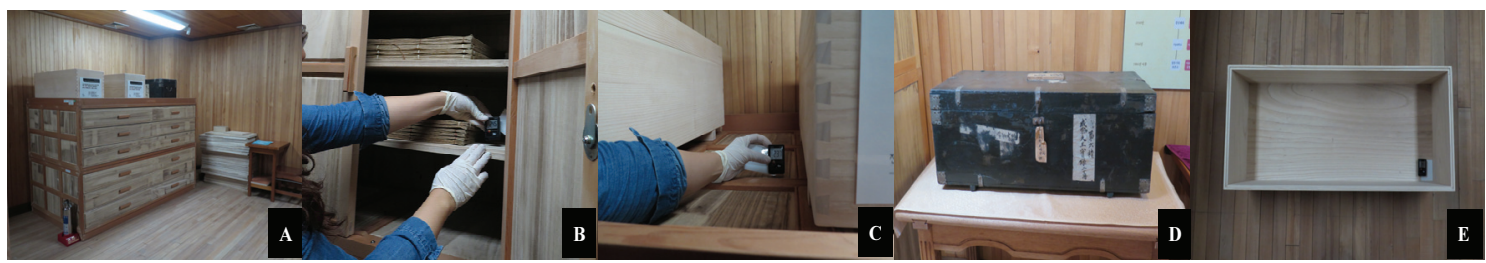

Figure 1. Indoor controlled storage space with thermo-hygrostat at the Kyujanggak Institute for Korean Studies (A: $P$. coreana and $P$. menziesii box, B: Sealed $P$. coreana furniture, C: P. coreana corridor, D: Old $P$. coreana box, and E: Newly fabricated $P$. coreana box).

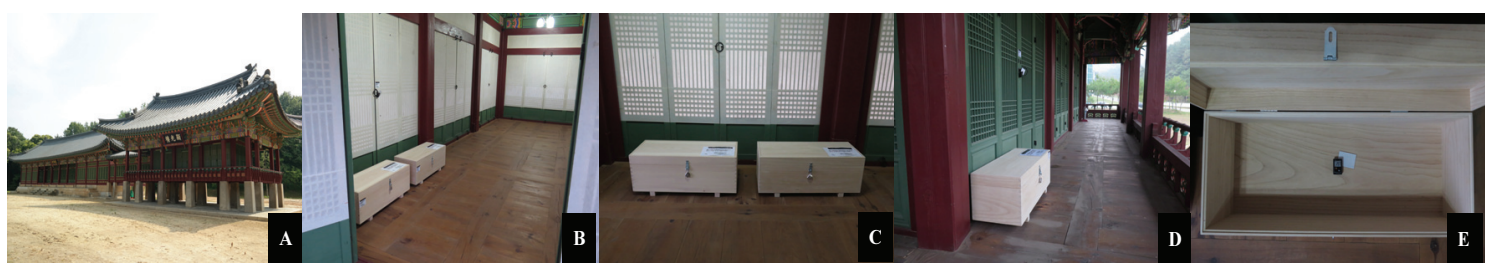

Figure 2. Indoor and outdoor uncontrolled traditional architecture without thermo-hygrostat at Anguk-dong detached palace, The Korea National University of Cultural Heritage (A: Overall building, B: Inner room, C: Newly fabricated $P$. coreana and $P$. menziesii box in a room, D: Newly fabricated $P$. coreana box in outdoors, and E: Inner $P$. coreana box with data logger). 
Before extraction process, the wood materials (sap wood) were sufficiently dried, cut into 1 to $3 \mathrm{~cm}$, and then powdered up into 700 meshes with a universal cutting mill (PULVERISETTE 19, FRITSCH, DEU) for an experiment.

The extracting process was divided into water-soluble extraction and volatile extraction to extract the active ingredient (Jeong et al., 2018). The water-soluble extraction was made by mixing $100 \mathrm{~g}$ of dried wood powder and $1000 \mathrm{~mL}$ of distilled water at $30^{\circ} \mathrm{C}$ for 72 hours. Then, the mixture of dried powers and extract was separated from the filter and volatile condensation was conducted with evaporator under the 50 to $70^{\circ} \mathrm{C}$. For volatile extraction, $100 \mathrm{~g}$ of wood powder was distilled into $125 \mathrm{~mL}$ of dichloromethane $\left(\mathrm{CH}_{2} \mathrm{Cl}_{2}\right)$ that had been re-extruded from the SDE device. And then sodium anhydrous sulfate $\left(\mathrm{Na}_{2} \mathrm{SO}_{4}\right)$ was added into the extract to remove the moisture and then condensed with $\mathrm{N}_{2}$ gas.

\subsection{Microbe repellent activity and antimicrobial activity test}

On 23th June of 2016, the microbe was collected with air-collector (Buck Bio-Culture ${ }^{\mathrm{TM}}$ Pump, A.P. Buck, Inc, USA) sampling $100 \mathrm{~L}$ of air twice through PDA (Potato Dextrose Agar) at a national storage room of the Kyujanggak Institute for Korean Studies where the Annals of the Joseon Dynasty has been preserved until now. Total 5 locations were selected to collect the microbe: 3 locations in $P$. corridor of storage room as open areas and 2 locations in sealed $P$. coreana furniture as a close area. The collected microbe was cultured in a $28^{\circ} \mathrm{C}$ incubator for 3 to 5 days; and after extracted DNA was analyzed with PCR and Automatic DNA sequencer, BlastN search was conducted at the genebank (NCBI, National Center for Biotechnology Information).

To evaluate the microbe repellent activity test, $150 \mu \mathrm{l}$ of a microbial suspension was inoculated on PDA and NA medium of which $P$. coreana samples $(20 \times 20 \times 15 \mathrm{~mm})$ were placed in middle and cultured to confirm the inhibition zone of the microbe formed around it. To assess the antimicrobial activity test with extract, $150 \mu \mathrm{l}$ of a microbial suspension was applied soaking on a paper disc and cultured in $28^{\circ} \mathrm{C}$ to confirm the inhibition growth formed around the paper disc.

\subsection{Insect repellent activity test}

Two typical species of insects were provided and used at the Institute of Preventive Conservation for Cultural Property, Korea National University of Cultural Heritage for insect repellent activity test: Reticulitermes speratus kyushuensis and Sitophilus oryzae. R. speratus kyushuensis was known as one of the main pests that have damaged the wooden cultural heritage and $S$. oryzae was often used for judging the fumigation effect in a field of conservation science. $R$. speratus kyushuensis was collected from Hapjeong-ri, Buyeo on April of 2016 and only repletes were used after breeding at room temperature and $\mathrm{RH} 90 \pm 5 \%$. S. oryzae was selected without distinction of their gender at $25 \pm 3{ }^{\circ} \mathrm{C}$ and $\mathrm{RH} 75 \pm 5 \%$ at a laboratory.

In this study, the insect repellent activity tests were divided into contact toxicity, fumigation toxicity and insect repellent tests. $0.5 \mu \mathrm{l}$ of extract was directly contacted to the thorax of 40 insects to identify whether they are confronted by death for the contact toxicity test. A close container method was applied for fumigation toxicity test; a filter paper soaking $100 \mu \mathrm{l}$ of extract was put in the bottom of lower plastic container $(65 \times 65 \times 100 \mathrm{~mm})$ and then 40 insects and their small amount of their food ( $R$. speratus kyushuensis: $2 \times 2 \mathrm{~cm}$ filter paper, $S$. oryzae: grains of rice) were put together to the upper container; test was conducted at RH $90 \pm 5 \%$ for 72 hours with 24 hours intervals with 3 times repeats. In a T-shaped container, both treated area with water-soluble and volatile extracts and untreated area with distilled water and dichloromethane were placed on both sides. And then 40 insects were placed in the middled of container for the repellent tests. The absorption process with extracts upon the treated and untreated area was carried out in same way with a fumigation toxicity test. The repellent test was conducted on water-soluble and volatile extract of $P$. coreana in the dark room for 24 hours with 3 repeats.

\section{RESULT}

\subsection{Temperature and relative humidity control}

A national storage room of the Kyujanggak Institute for Korean Studies showed little monthly average temperature difference because the temperature and relative humidity have 
kept constant with thermo-hygrostat equipment from October of 2015 to September of 2016. The monthly average temperature ranged minimum $19.0^{\circ} \mathrm{C}$ to maximum $21.3^{\circ} \mathrm{C}$; and monthly average relative humidity was in range of $52.6 \%$ to $60.7 \%$ inside the controlled storage room. There was little temperature difference depending on its locations from uncontrolled traditional space without any thermo-hygrostat systems at Anguk-dong detached palace and it indicates the outside circumstances influenced the monthly average temperature of the indoor and outdoor spaces (Figure 3).

Measuring the monthly average relative humidity for 4 seasons under uncontrolled spaces, inner $P$. coreana boxes exposed to the outside followed the relative humidity of the outside. They are measured higher in fall season (77.7\%) than hot and humid summer season (72.7\%) and the lowest was in spring season (61.0\%). And under the controlled circumstances, there was no significant difference between the old $P$. coreana box and the newly fabricated $P$. coreana and P. menziesii box (Figure 4).

The monthly average daily temperature range of the outside was the highest in spring (March) and lowest in fall season (September). On spring of 2016, the average daily temperature range was $13.5^{\circ} \mathrm{C}$ in outside and $11.4^{\circ} \mathrm{C}$ in the inner $P$. coreana boxes exposed to the outside; that of inner $P$. coreana boxes installed in the uncontrolled room was $9.8^{\circ} \mathrm{C}$; and those of inner $P$. coreana furniture and boxes installed in a controlled storage room ranged from $0.5^{\circ} \mathrm{C}$ to $0.9^{\circ} \mathrm{C}$. It indicates that this was based on the outside weather $\left(13.5^{\circ} \mathrm{C}\right)$

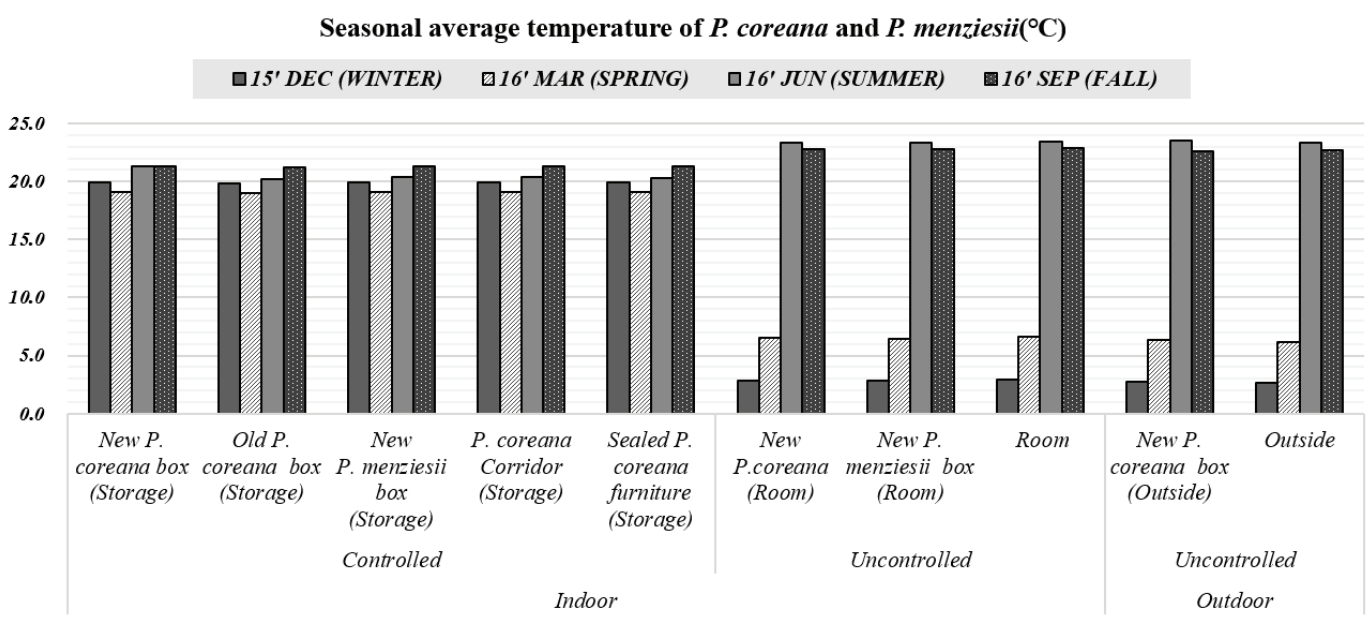

Figure 3. Result of seasonal average temperature of $P$. coreana and $P$. menziesii under the controlled and uncontrolled surroundings in 2015 and 2016.

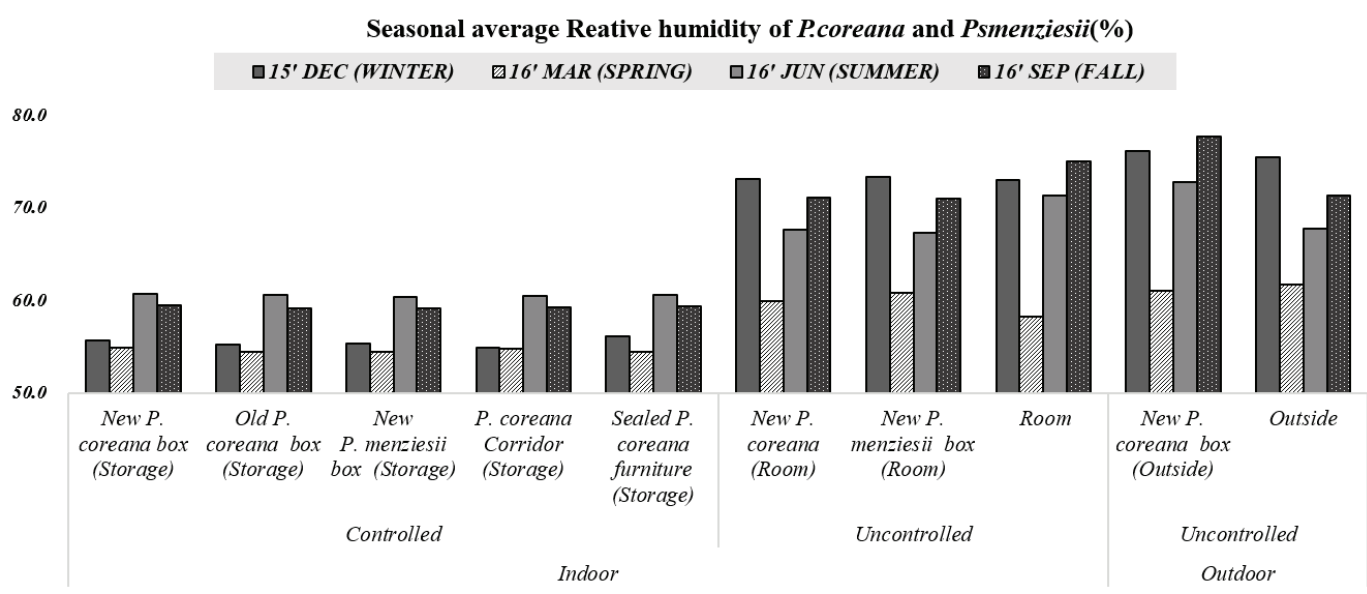

Figure 4. Result of seasonal average relative humidity of $P$. coreana and $P$. menziesii under the controlled and uncontrolled surroundings in 2015 and 2016. 
and $P$. coreana boxes show a good buffering effect to adjust the monthly average daily temperature range from the outside; the different buffering degrees of a daily temperature range was confirmed depending on the locations: inner $P$. coreana wooden boxes installed in the outside $\left(2.1^{\circ} \mathrm{C}\right)$, inner $P$. coreana and P. menziesii storage wooden box in uncontrolled room $\left(3.7^{\circ} \mathrm{C}\right.$ and $\left.3.8^{\circ} \mathrm{C}\right)$ under the uncontrolled circumstances. And, the average daily temperature range of inner old $P$. coreana heritage and newly fabricated $P$. coreana box was same under the controlled space (Figure 5).

Overall, the average daily relative humidity ranges were as high in a row of spring (March), summer (June), winter (December) and fall (September) season of 2015 and 2016. In December, the humidity self-control capacity of inner boxes

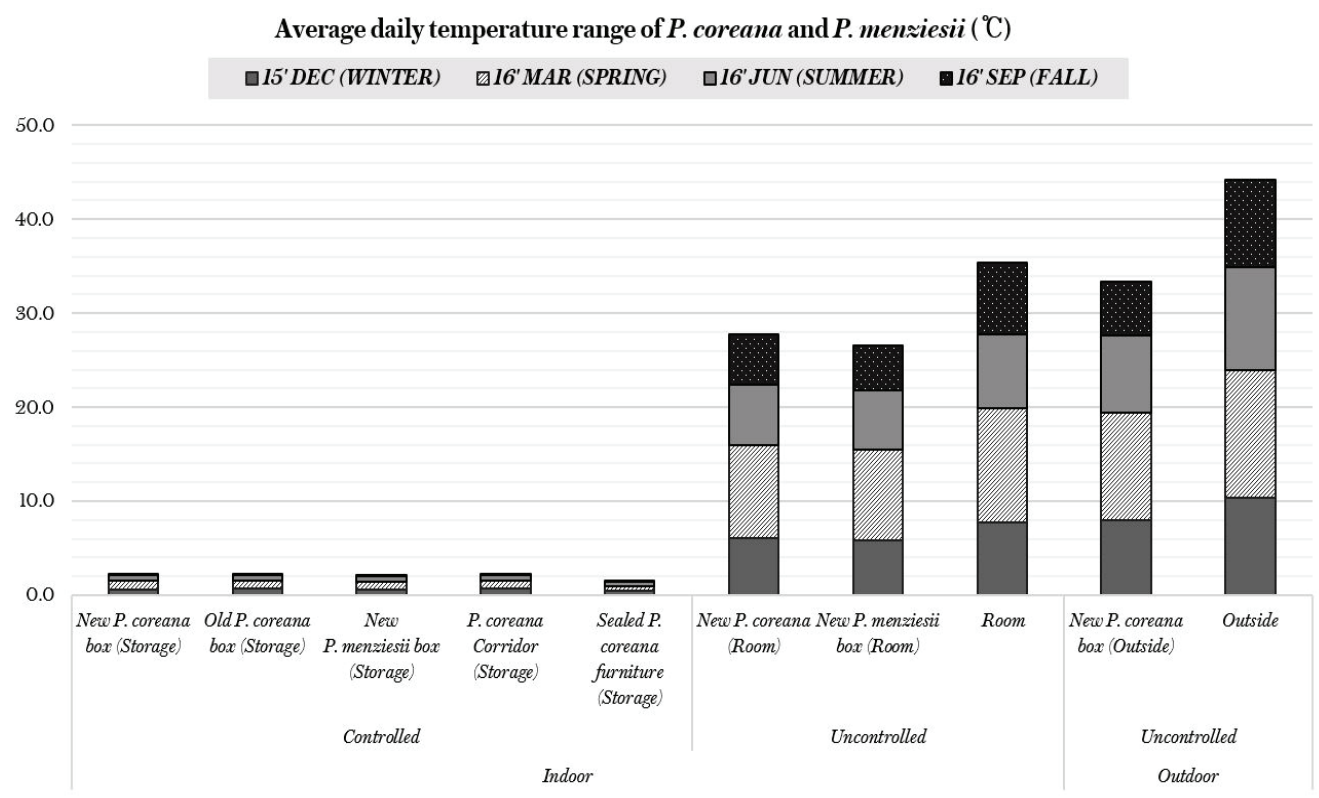

Figure 5. Result of average daily temperature range of inner P. coreana and P. menziesii in controlled and uncontrolled surrounding $\left({ }^{\circ} \mathrm{C}\right)$.

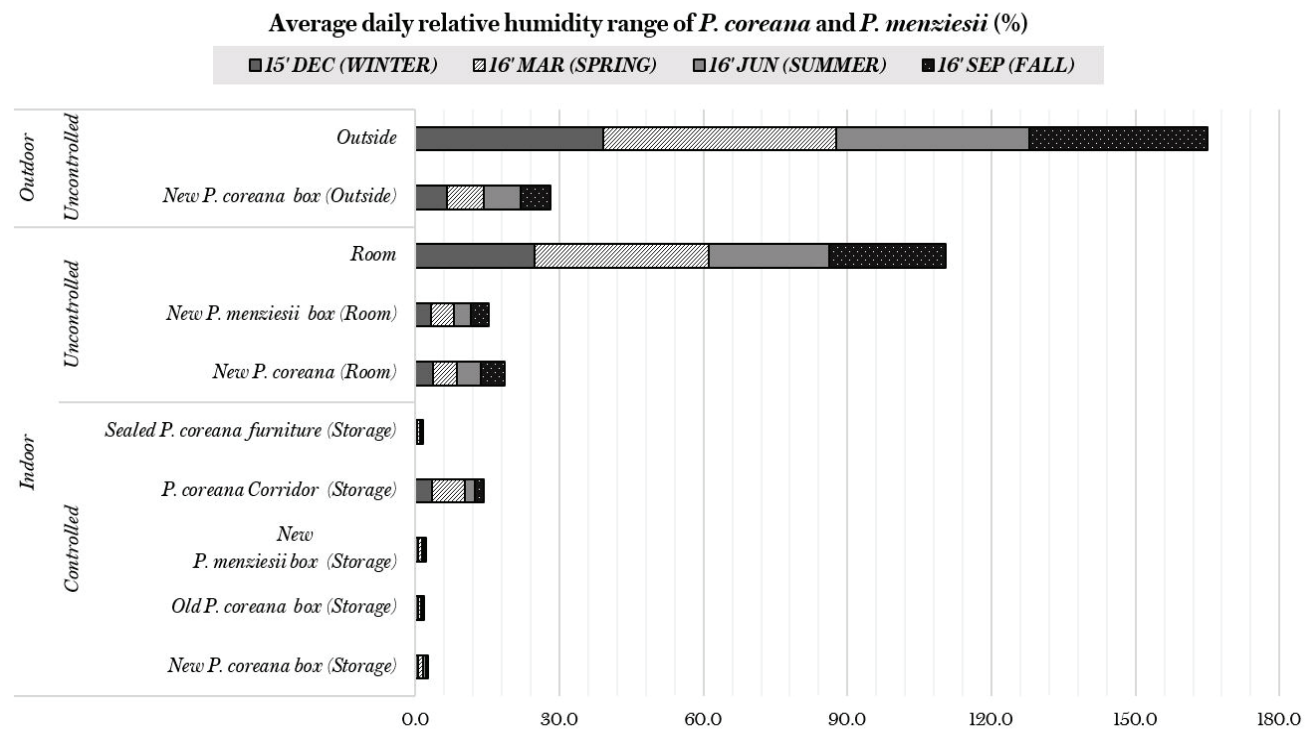

Figure 6. Result of average daily relative humidity range of inner $P$. coreana and $P$. menziesii in controlled and uncontrolled surrounding (\%). 
(3.7\% of average daily temperature range) was confirmed to $0.5 \%$ lower than that of the P. menziesii storage box (3.2\%). In March, the humidity control capacity was increased under the controlled storage in the order of the newly fabricated P. coreana box (1.0\%), new P. menziesii box $(0.9 \%)$ and old $P$. coreana box $(0.7 \%)$. In the spring season when the daily relative humidity range was the highest, buffering capacity for a daily humidity range showed $41.0 \%$ of the inner newly-fabricated $P$. coreana box installed in the outside as an uncontrolled space while daily relative humidity variability of the outdoor was 48.6\%; and those of inner newlyfabricated $P$. coreana and $P$. menziesii box in an uncontrolled room were $43.6 \%$ and $43.9 \%$. And the humidity control capacity of the $P$. coreana corridor where the indoor air moved inside the controlled storage was $0.6 \%$ lower than inner $P$. coreana furniture or box in a controlled storage room during the summer season of 2016 (Figure 6).

\subsection{Microbe repellent activity and antimicrobial activity tests}

Fungi was inoculated in a PDA medium and bacteria was conducted in a NA (Nutrient Agar) for 3 to 5 days in $28^{\circ} \mathrm{C}$ incubator until the microbial growth was visible to the naked eye. Through morphological separation, airborne microorganisms were isolated into 4 fungi and 5 bacteria, and the genetic analysis showed that the analyzed species were Phaeosphaeriaceae sp., Staphylococcus aureus and so on (Table 1).

The microbe repellent activity test was conducted to evaluate that the extracted materials can control the growth of microorganisms that target the surface wood, leading to contamination and/or discoloration. The result of the microbe repellent activity confirms that $P$. coreana and $P$. menziesii do not have any microbe repellent substances so the growth of inhibition zones was not formed for 4 fungi and 5 bacteria (Figure 7).

Table 1. Result of genetic analysis with microbe and bacteria

\begin{tabular}{cccccc}
\hline No. & Description & Accession & No. & Description & Accession \\
\hline JF1 & Phaeosphaeriaceae sp. & KU255073.1 & JB1 & Staphylococcus aureus & LC107806.1 \\
\hline JF2 & Phoma sp. & JQ838011.1 & JB2 & Bacillus cereus & LN827673.1 \\
\hline JF3 & Ascomycota sp. & JN850978.1 & JB3 & Chryseobacterium hominis & AM423087.1 \\
\hline JF4 & Pseudotaeniolina globosa & KC311489.1 & JB4 & Staphylococcus hominis & EU337115.1 \\
\hline- & - & - & JB5 & Dermacoccus sp. & JF905611.1 \\
\hline
\end{tabular}
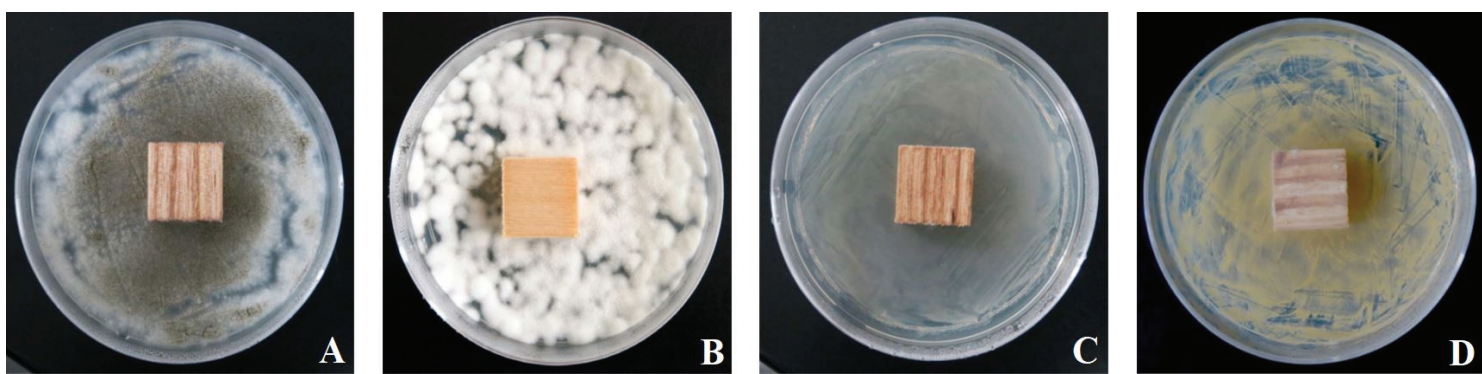

Figure 7. Result of microbe repellent activity of $P$. coreana (A: CF1, B: JF1, C: JB3, and D: JB5).
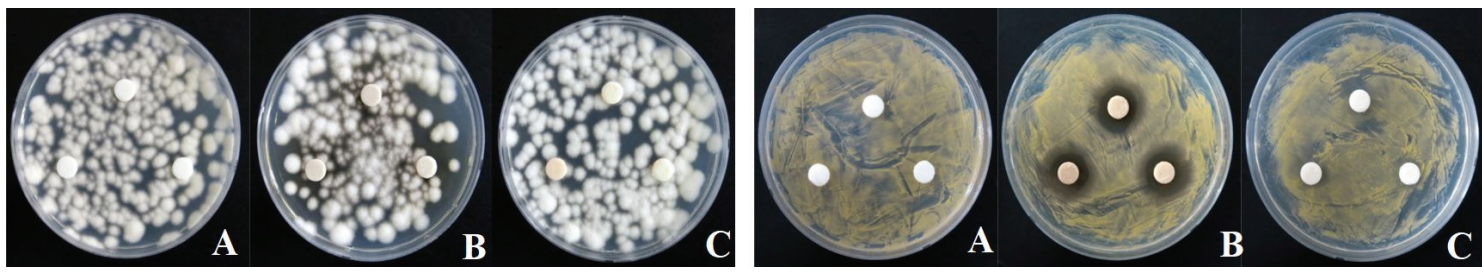

Figure 8. Result of antimicrobial activity of JF3 (left) and JF5 (right) with water-soluble extraction (A: distilled water, B: P. coreana, and C: P. menziesii). 

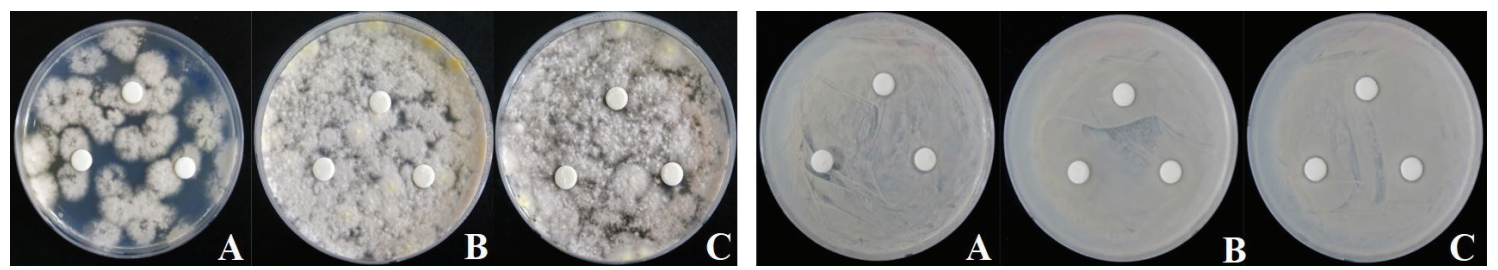

Figure 9. Result of antimicrobial activity of JF2 (left) and JB2 (right) with volatile extraction (A: dichloromethane, B: P. coreana, and C: P. menziesii).

Table 2. Result of microbe repellent activity and antimicrobial activity of the extract (Growth and deterioration activity grade: none(-), weak $(+)$, average $(++)$, strong $(+++))$

\begin{tabular}{|c|c|c|c|c|c|c|c|c|c|}
\hline \multirow{3}{*}{ No. } & \multirow{3}{*}{ Description } & \multicolumn{2}{|c|}{$\begin{array}{c}\text { Microbe repellent } \\
\text { activity }\end{array}$} & \multicolumn{6}{|c|}{ Antimicrobial activity } \\
\hline & & \multirow{2}{*}{$\begin{array}{c}P . \\
\text { coreana }\end{array}$} & \multirow{2}{*}{$\begin{array}{c}P . \\
\text { menziesii }\end{array}$} & \multicolumn{3}{|c|}{ Water-soluble extraction } & \multicolumn{3}{|c|}{ Volatile extraction } \\
\hline & & & & $\begin{array}{l}\text { Distilled } \\
\text { water }\end{array}$ & $\begin{array}{c}P . \\
\text { coreana }\end{array}$ & P.menziesii & $\begin{array}{c}\text { Dichloro-methane } \\
\left(\mathrm{CH}_{2} \mathrm{Cl}_{2}\right)\end{array}$ & $\begin{array}{c}P . \\
\text { coreana }\end{array}$ & $\begin{array}{c}P . \\
\text { menziesii }\end{array}$ \\
\hline CF1 & Aspergillus niger & - & - & - & - & - & - & - & - \\
\hline JF1 & Phaeosphaeriaceae sp. & - & - & - & - & - & - & - & - \\
\hline $\mathrm{JF} 2$ & Phoma sp. & - & - & - & - & - & - & - & - \\
\hline JF3 & Ascomycota sp. & - & - & - & - & - & - & - & - \\
\hline JF4 & Pseudotaeniolina globosa & - & - & - & - & - & - & - & - \\
\hline JB1 & Staphylococcus aureus & - & - & - & + & - & - & - & - \\
\hline JB2 & Bacillus cereus & - & - & - & + & - & - & - & - \\
\hline JB3 & Chryseobacterium hominis & - & - & - & ++ & - & - & - & - \\
\hline JB4 & Staphylococcus hominis & - & - & - & + & - & - & - & - \\
\hline JB5 & Dermacoccus sp. & - & - & - & ++ & - & - & - & - \\
\hline
\end{tabular}

Antimicrobial activity tests were performed to confirm whether the wood extract inhibited the growth of microorganisms. In case of the fungi tested, the water-soluble extracts of $P$. coreana and $P$. menziesii did not produce clear zones of growth inhibition, indicating that these extracts do not have any antifungal properties. Meanwhile, the antibacterial activity tests revealed growth inhibition of five bacteria by the water-soluble extract of $P$. coreana, with clear zones ranging from 0.05 to $0.5 \mathrm{~cm}$ around the paper disc containing the extract (Figure 8 ). However, no antibacterial activity was observed for the water-soluble extract of $P$. menziesii. Notably, the volatile extracts from $P$. coreana and $P$. menziesii, including dichloromethane, did not produce growth inhibition zones in the antimicrobial activity tests. Thus, based on the antifungal and antibacterial activity tests, it was concluded that the volatile extracts from both $P$. coreana and $P$. menziesii do not affect the growth of fungi and bacteria (Figure 9, Table 2). Moreover, we determined that antifungal substances were not present in these extracts.

\subsection{Insect repellent activity}

In the contact toxicity test, it was clear that $R$. speratus kyushuensis and $S$. oryzae were not identified toward the water-soluble extract whereas a large number of insects were identified with volatile extracts. This seems to be influenced by the solvent rather than the extract components since there is no significant difference from a control group, dichloromethane itself. The contact toxicity with both $R$. speratus kyushuensis and $S$. oryzae was equally ineffective in watersoluble extracts, and the effect from the volatile extracts was confirmed to be due to extracting solvent (Figure 10).

Monitoring for 3 days with fumigation toxicity tests of water-soluble extracts, $R$. speratus kyushuensis was active after 3 days and $S$. oryzae was reduced to average 3.2 insects after 3 days. This was confirmed that the numbers of both 


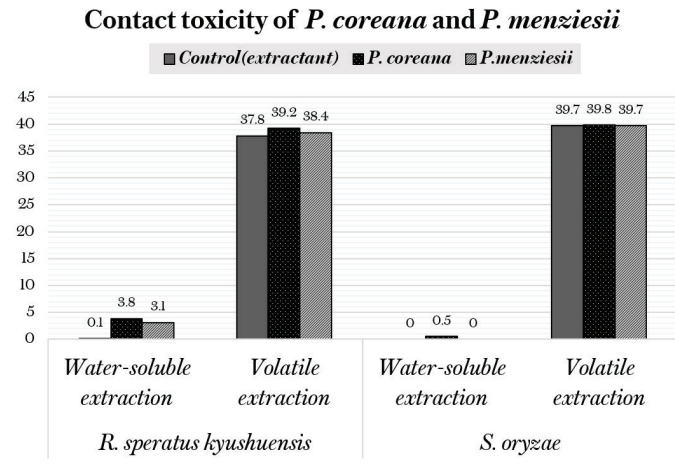

Figure 10. Result of contact toxicity of $R$. speratus kyushuensis and $S$. oryzae with extract.

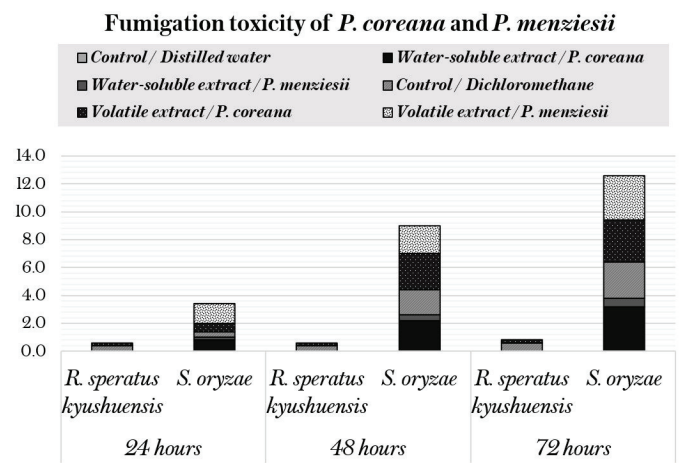

Figure 11. Result of fumigation toxicity of $R$. speratus kyushuensis and S. oryzae with extract.

$R$. speratus kyushuensis and $S$. oryzae were reduced by natural death, not by extracts; volatile extract is also considered to have no fumigation toxicity effect due to the small numbers of dead insects (Figure 11). Also, both R. speratus kyushuensis and $S$. oryzae freely moved toward both areas where the water-soluble and volatile extracts were absorbed and control areas with distilled water or dichloromethane in the repellent test. Therefore, these extracts from $P$. coreana and $P$. menziesii do not have any insect repellent so $R$. speratus kyushuensis and S. oryzae do not avoid the extracts.

\section{CONCLUSION}

The temperature and relative humidity control of $P$. coreana, which is widely used for the storage of the cultural heritage, was evaluated under the controlled and uncontrolled circumstances from 2015 to 2016. In this study, seasonal and daily change of temperature and relative humidity was mea- sured to identify the self-control ability of $P$. coreana and it shows to be mainly excellent in humidity control. In spring season, when the daily relative humidity range was the highest, buffering capacity for a daily humidity range showed $41.0 \%$ of the inner newly-fabricated $P$. coreana box installed in the outside as an uncontrolled space while daily relative humidity range of the outdoor was $48.6 \%$; and those of inner newly-fabricated $P$. coreana and $P$. menziesii box in an uncontrolled room were $43.6 \%$ and $43.9 \%$. In winter and summer seasons, inner newly-fabricated $P$. coreana box installed outside shortened $32.5 \%$ gap of monthly average daily relative humidity range from the outside.

These results suggest that the circumstance control ability of wood box can shorten a sudden change period in case of an emergency situation where it is difficult to operate or control the constant temperature and relative humidity by unexpected breakdown or shutdown of the thermo-hygrostat in museums, libraries or art galleries. Based on the environmental data established in this, it is considered that further researches on the humidity control ability are needed with more detailed environment conditions whether there are archival and traditional binding books in a storage box or how many books are preserved in it because the papers can serve as a positive buffer agents with good humidity control ability together along the storage boxes. And then it is expected that these results will be applied in various ways to produce the manuals for integrated management and longterm preservation of cultural heritage in near future.

Also, microbe repellent activity, antimicrobial activity test and insect repellent test were experimented with watersoluble and volatile extracts from $P$. coreana. Its results concluded that P.coreana has no antifungal and antibacterial substances toward 9 different types of microbe collected at a storage space and inner furnitures made with its material. However, growth inhibition sized to 0.05 to $0.5 \mathrm{~cm}$ was observed around the paper disc applying with the watersoluble extract of $P$. coreana toward 5 bacteria; in particular, JB3 and JB5 showed growth inhibition zones so that this indicates water-soluble extract of $P$. coreana had a weak antibacterial activity.

The water-soluble extract of $P$. coreana wasn't effective to 2 types of insects as $R$. speratus kyushuensis and $S$. oryzae in the contact toxicity test; and water-soluble and volatile extracts also could not affect the fumigation effect to insects 
in the fumigation toxicity test. And insects can approach freely toward the material itself extracted from $P$. coreana without any repellent in a repellent test. Following the published research, it coincides the conventional heritage storage box material, $P$. coreana, was not good enough for antimicrobial property (Chung et al., 2008). Additionally, despite its customary use, it reported there are many disadvantages on electromagnetic wave blocking, gas absorption, alkali resistance, low strength for storing heavy materials, weather resistance and gas adsorption (National Research Institute of Cultural Heritage, 2009).

Summarizing these results, it can be judged that $P$. coreana does not prevent the biological deterioration when the pest comes into contact and/or attempted to attack it. Based on the integrated results, we cannot expect $P$. coreana boxes, which are widely used for the preservation of heritage materials, to have insecticidal or antibacterial properties. So we are planning to study further on the correlation between humidity and microbial growth in the future.

\section{REFERENCES}

Cho, H.J., 2011, A Survey into the Environment of National and Public Art Museum Storage and a Study on Joint Storage. Journal of the Korea Institute of the Spatial Design, 6(2), 53-60. (in Korean with English abstract)
Chung, Y.J., Kang, S.Y. and Choi, Y.A., 2008, Analysis on antifungal activity of Paulownia-wood storage box and application of natural biocide for the activity enhancement. Journal of Conservation Science, 24, 75-83. (in Korean with English abstract)

Jeong S.H., Lee, H.J., Kim, D.W. and Chung, Y.J., 2018, New biocide for eco-friendly biofilm removal on outdoor stone monuments. International Biodeterioration \& Biodegradation, 131, 19-28.

Lee, S.E., Roh, H.S. and Yi, Y.H., 2004, Effects of wood materials on metal corrosion - Oddy test - Conservation Science in Museum, 5, 31-36. (in Korean with English abstract)

National Research Institute of Cultural Heritage, 2009, Property characterization and safety evaluation of cultural heritage storage box. 1-82. (in Korean)

Park, J.S., 2005, Study on humidity control performance of the interior finishing materials of museum collection storage: focused on comparisons between natural timber and artificial humidity control materials. Master's thesis, Yonsei University, Seoul, 46-53 (in Korean with English abstract)

Song, J.A. and Park, W.K., 2010, Species of Korean Furniture in the Late Choseon Dynasty(I). Journal of the Korea furniture Society, 21(6), 486-498. (in English with Korean abstract) 